\title{
EFEITO DE DIFERENTES DOSES DE 2,4-D, APLICADO COMO DESSECANTE EM VARIOS INTERVALOS ANTES DA SEMEADURA DIRETA DA SOJA, PARA MANEJO EM AMBIENTE DE CERRADOS
}

\author{
Tarcísio de O. Valente ${ }^{1}$, Edson T. Rodrigues ${ }^{1}$ e Maurício A. Cavazzana ${ }^{2}$
}

\author{
Engenheiro Agrônomo, MSc, Professor. Universidade Federal de Mato Grosso do Sul. Caixa Postal 533. Dourados, MS 79804-970. \\ tvalente@ceud.ufms.br \\ ${ }^{2}$ Acadêmico de Agronomia. FEIS/UNESP. Av. Brasil, 56. Caixa Postal 31. Ilha Solteira, SP 15385-000
}

\begin{abstract}
RESUMO
O experimento foi conduzido em solo originalmente sob vegetação de Cerrado com textura leve. Utilizou-se para dessecação da cobertura vegetal, composta de plantas daninhas com predominância de Commelina benghalensis, o herbicida 2,4-D amina nas doses de 72, 144, 216, 288, 432, 576 e $720 \mathrm{~g} / \mathrm{ha}$, aplicadas em uma única vez. A semeadura da soja foi feita com um, dois, três, quatro, cinco, oito e dez dias após a dessecação. Os tratamentos foram constituídos pelas épocas de semeadura da soja após a aplicação do herbicida, combinadas com as doses do 2,4-D, no delineamento em blocos casualizados com três repetições. Avaliou-se a densidade e o crescimento das plantas de soja, através da medição da altura das plantas aos 45 dias após a semeadura e na pré-colheita, altura da inserção da primeira vagem, peso de grãos por planta e produtividade. Os resultados demonstraram que todas as variáveis analisadas foram influenciadas pelo herbicida quando aplicado de um até cinco dias antes da semeadura da soja. A produtividade, embora não tenha sido influenciada significativamente pelas épocas de semeadura, foi sensivelmente reduzida com o aumento das doses do herbicida. Mesmo em baixa concentração, o 2,4-D afetou o crescimento da soja nas seis épocas de semeadura após a aplicação. Desse modo, o uso do 2,4-D poderá ser recomendado para solos leves de Cerrados, nas aplicações de dessecação, até a dose de $720 \mathrm{~g} / \mathrm{ha}$, desde que aplicado com um intervalo mínimo de 8 dias antes da semeadura direta da soja.
\end{abstract}

Palavras-chave: herbicida, plantio direto, Glycine max, Commelina benghalensis.

\author{
ABSTRACT \\ Use of 2,4-D as a burndown treatment for soybeans in no-till \\ cropping systems in the Cerrados region
}

A field experiment was carried out in the Cerrados region in Rondonópolis, MT, Brazil, in order to evaluate the behavior of 2,4-D amine, applied alone and as a pre-site preparation at 72, 144, 216, 288, 432, 576 and 720 grams per hectare, to control the weed spectrum in no-till soybean. Commelina benghalensis was the predominant weed species. Soybean was seeded at 1, 2, 3, 4,5,8 and 10 days after burndown treatment and the planting timing was crossed with 2,4-D rates, applied in a randomized block design in three replications. The crop response as measured by stand and plant height was evaluated at 45 days after spraying and as a pre-harvest evaluation at the first pod insertion. The number of pods per plant, dry weight and productivity were assessed. The results showed that all the variables analyzed were affected by the herbicide when soybean was planted up to 5 days after spray treatment. Considering only the planting time, the productivity was not statistically different, however it was 
significantly reduced when the rates of 2,4-D were increased. Even at the lower rate, a plant growth reduction was observed. As conclusion, 2,4-D amine can be recommended as a burndown treatment for Cerrados sandy soil, up to $720 \mathrm{~g} / \mathrm{ha}$, since soybeans are planted at least 8 days after the herbicide application.

Key words: herbicide, Glycine max, Commelina benghalensis.

\section{INTRODUÇÃO}

O plantio direto, expandiu-se no Brasil nos últimos anos, chegando a ocupar uma área de mais de doze milhões de hectares, sendo a soja a principal cultura utilizada (Saturnino, 1999). Como exemplo da importância das plantas daninhas, uma população de dicotiledôneas com 112 indivíduos/m ${ }^{2}$, pode provocar uma perda na produção na ordem de $42 \%$ (Blanco et al., 1978). Várias espécies de plantas daninhas, como fedegoso (Senna obtusifolia),por exemplo, tem sido motivo de preocupação quanto ao seu controle na cultura da soja, por pertencer à mesma família da soja e apresentar exigências nutricionais semelhantes tornando a competição entre as espécies mais acirrada. Thurlow et al. (1972), citados por Blanco et al. (1978), verificaram, também, que foi de 15 dias a duração do período crítico de competição entre $S$. obtusifolia e a soja. Blanco et al. (1978) relataram que o período crítico de competição com a soja situa-se entre 30 e 45 dias após a emergência da cultura. As plantas com características pioneiras, sem sucesso adaptativo no sistema convencional, podem ser favorecidas com o plantio direto e ter suas populações incrementadas (Pitelli, 1997).

A dessecação da cobertura vegetal para a posterior semeadura direta da soja, seja cultura secundária ou plantas daninhas, é feita com um dos dessecantes glyphosate, sulphosate, diquat ou paraquat (Rodrigues et al., 1998). Quando se utilizam os dessecantes sistêmicos é comum misturar o herbicida 2,4-D para melhorar a translocação dos produtos na planta. O herbicida 2,4-D é tóxico para a cultura da soja mesmo utilizado na dessecação, porque o seu efeito residual no solo é de aproximadamente dez dias (Rodrigues et al., 1998). Pesquisas revelam que esse herbicida aumenta a velocidade de translocação do glypphosate ou do sulphosate dentro da planta, facilitando o acesso dos produtos aos meristemas, o que confere a melhoria da eficiência. Os produtos glyphosate ou sulphosate possuem mecanismos de ação diferentes do 2,4-D (Vidal, 1997) e, quando misturados, possuem um efeito sinérgico que possibilita o aumento da eficiência de controle e do espectro de ação dos produtos.

Embora resultados de pesquisas mostrem a viabilidade técnica da mistura do 2,4-D com um dessecante sistêmico (glyphosate ou sulphosate), para a dessecação da cobertura vegetal na semeadura direta da soja, é preciso analisar as recomendações de uso devido às restrições existentes quanto ao uso do herbicida 2,4-D nesta modalidade de aplicação (EMBRAPA, 1995).
Nas condições de solos sob Cerrado com baixos teores de matéria orgânica e texturas leves, caracterizados por baixos teores de argila e altos teores de areia. Almeida \& Rodrigues (1985) e Rodrigues \& Almeida (1998) recomendam um intervalo de dez dias entre a aplicação para dessecação e a semeadura da soja. Todavia, tem-se verificado reduções desse intervalo de segurança em extensas áreas de Cerrado cultivadas com soja.

Este trabalho teve como objetivo verificar o efeito residual de 2,4-D aplicado como dessecante, para semeadura direta da soja em ambiente de Cerrado.

\section{MATERIAL E MÉTODOS}

O ensaio foi conduzido em Latossolo Vermelho-Amarelo fase Cerrado, na Fazenda SM2 da Sementes Maggi, município de Rondonópolis, MT, durante a safra 1999/2000. A variedade de soja Uirapuru foi semeada nos dias 20, 21, 22, 23, 24, 27 e 29/12/99, utilizando o espaçamento de 0,5 m entre linhas e a densidade de 16 sementes por metro linear. A adubação foi feita com $450 \mathrm{~kg} / \mathrm{ha}$ da fórmula 00-20-20, em sistema de semeadura direta. Os resultados da análise física do solo apresentaram $49,9 \%$ de areia, $43,4 \%$ de argila e $6,7 \%$ de silte. $O$ $\mathrm{pH}$ em água foi 5,8 e a matéria ợgânica $29 \mathrm{cmol} / \mathrm{dm}^{3} \mathrm{e} C \mathrm{CTC}$ de $8,3 \mathrm{~mol} / \mathrm{dm}^{3}$.

Os tratos culturais seguiram as recomendações técnicas para a região (EMBRAPA-CPAO, 1995). A aplicação do 2, 4-D foi feita em uma única vez, no dia 19/12/99, utilizando-se um pulverizador manual pressurizado a gás carbônico, mantido à pressão constante de $30 \mathrm{psi}$, contendo uma barra com quatro bicos espaçados de $0,5 \mathrm{~m}$, portando pontas de jato plano XR110.02 e proporcionando um volume de calda de 200 $1 /$ ha. As plantas daninhas que formavam a cobertura vegetal encontravam-se em fase final da floração, com predominância de Commelina benghalensis.

O experimento consistiu das épocas de semeadura em um, dois, três, quatro, cinco, oito e dez dias após a aplicação do herbicida 2,4-D, combinadas com as doses de 0, 72, 144, $216,288,432,576$ e $720 \mathrm{~g} / \mathrm{ha}$, no esquema fatorial 7 x 8, delineamento em blocos casualizados com três repetições. As parcelas foram constituída por três linhas de cultivo da soja, espaçadas de 0,5 m. A aplicação foi feita em condições favoráveis ao bom desempenho dos produtos, ou seja, com temperatura de $27^{\circ} \mathrm{C}$ e $68 \%$ de umidade relativa do ar. As precipitações ocorridas são apresentadas na Tabela 1 e Figura 1. 
Tabela 1. Precipitação $(\mathrm{mm})$ ocorrida de dezembro de 1999 a fevereiro de 2000, no local de condução do experimento. Rondonópolis-MT, 1999/2000.

\begin{tabular}{lccc}
\hline \multicolumn{1}{r}{ Período } & Dezembro & Janeiro & Fevereiro \\
\hline 1 a 10 & 114 & 55 & 109 \\
11 a 20 & 121 & 28 & 255 \\
21 a 31 & 51 & 123 & 33 \\
\hline Total do Mês & 286 & 206 & 397 \\
\hline
\end{tabular}

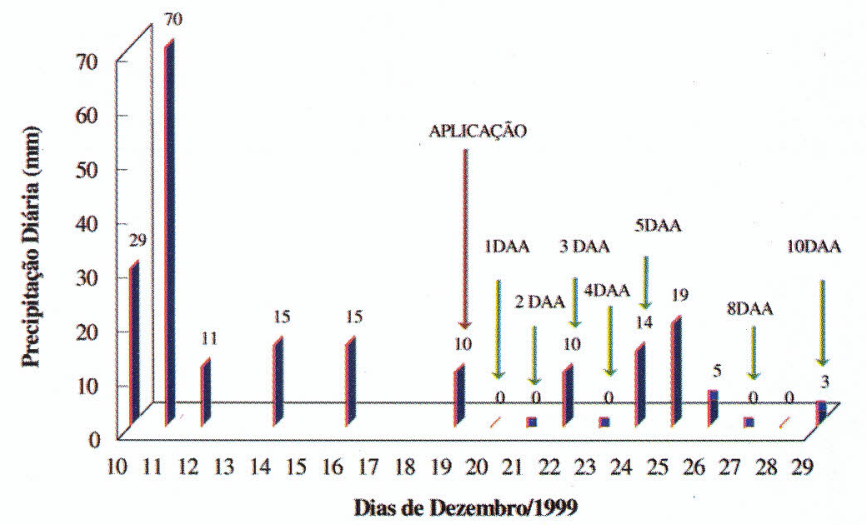

Figura 1. Precipitação diária ocorrida no período de condução do experimento com detalhe da época de aplicação das doses do herbicida 2,4-D e das épocas de semeadura da soja após a dessecação. Rondonópolis-MT, 1999/2000.

O crescimento das planta foi avaliado por meio do estande inicial, número de plantas emergidas em três pontos por parcela. Foi também avaliada a altura aos 45 dias após a semeadura, assim como durante a pré-colheita, medindo da região do colo ao ápice da planta, em $\mathrm{cm}$, além da altura da inserção da primeira vagem. O peso de grãos por planta e a produtividade foram determinados quando os grãos encontravam-se com $10 \%$ de umidade. Os dados foram submetidos à análise de variância por meio do programa de computador SAEG (Sistema Para Análises Estatísticas) (Euclydes, 1997). As variáveis que apresentaram o efeito de doses de herbicida significativo foram submetidas à análise de regressão, com o intuito de se ajustarem equações relacionando a variável em função das doses.

\section{RESULTADOS E DISCUSSÃO}

Os resultados apresentados na Tabela 2 demonstram que o número de plantas por metro linear foi reduzido significativamente até o quarto dia após aplicação do herbicida, tendo-se verificado uma diminuição do número de plantas também em função do aumento das doses de 2,4-D (Figura 2).

A altura de inserção da primeira vagem foi maior no primeiro dia após a aplicação, diferindo estatisticamente das demais épocas (Tabela 2). Observa-se que não houve precipitação pluviométrica até ao segundo dia após a aplicação do 2,4-D (Figura 2), o que pode ter dificultado a sua lixiviação na palha e no solo. A ocorrência das chuvas nos primeiros dias, coincidindo as fases da germinação, afetou drasticamente o estande (Figuras 2 e 6). O menor número de plantas por metro linear diminuiu a competição intraespecífica, favorecendo um maior crescimento das plantas remanescentes e da altura na inserção da primeira vagem, para as plantas semeadas no primeiro dia após a aplicação.

A altura das plantas medida aos 45 dias após a semeadura foi significativamente influenciada pelas doses, pelas épocas e pela interação desses fatores. Somente a partir do oitavo dia após a semeadura, as plantas atingiram seu crescimento médio máximo (Tabela 2).

No primeiro dia de semeadura (1DAA), a média da altura das plantas foi a mais baixa, apresentando uma queda brusca a partir da menor dose de 2,4-D (Figura 4). Isto se deve ao fato de que em baixas concentrações esse herbicida atua como regulador de crescimento, provocando um desbalanceamento na concentração hormonal da planta (Vidal, 1977). No segundo, terceiro e quinto dia após a aplicação, a altura das plantas aos 45 dias após a aplicação foi significativamente afetada (Tabela 2), com desempenho inferior a semeadura realizada aos 8 e 10 dias após a aplicação (Figura 4). A partir do oitavo dia da semeadura após a aplicação, as plantas apresentaram o melhor desempenho (Tabela 2 e Figura 4). Os resultados observados neste experimento confirmam as recomendações feitas anteriormente por Almeida \& Rodrigues (1985) e Rodrigues \& Almeida (1998).

A produtividade, embora não tenha sido influenciada significativamente nas diferentes épocas (Tabela 2), foi sensivelmente reduzida com o aumento das doses (Figuras 3 e 5) em função da média das épocas de semeadura, confirmando o efeito depreciativo exercido pelo herbicida em períodos próximos à dessecação.

A redução do número de plantas por metro linear foi visivelmente maior com o aumento das doses do herbicida 2,4-D, nos primeiros dias após a aplicação, principalmente nas épocas próximas da dessecação (Figura 6). 
Tabela 2. Valores médios do número de plantas por metro linear (STD), altura da planta aos 45 dias (ALT45), na pré-colheita (ALTPRE), altura de inserção da primeira vagem (ALTPV), peso de grãos por planta (PGPP), e produtividade(PROD), em diferentes épocas de semeadura, em função da média das doses de 2,4-D. Rondonópolis-MT, 1999/2000.

\begin{tabular}{ccccccc}
\hline $\begin{array}{c}\text { Dias após a } \\
\text { aplicação }\end{array}$ & STD & $\begin{array}{c}\text { ALT45 } \\
(\mathbf{c m})\end{array}$ & $\begin{array}{c}\text { ALTPRE } \\
(\mathbf{c m})\end{array}$ & $\begin{array}{c}\text { ALTPV } \\
(\mathbf{c m})\end{array}$ & $\begin{array}{c}\text { PGPP } \\
(\mathbf{g})\end{array}$ & $\begin{array}{c}\text { PROD } \\
(\mathbf{k g} / \mathbf{h a})\end{array}$ \\
\hline 1 & $10,8 \mathrm{~b}^{1}$ & $34,3 \mathrm{~d}$ & $68,2 \mathrm{ab}$ & $12,8 \mathrm{a}$ & 54,6 & $2696,6 \mathrm{a}$ \\
2 & $10,4 \mathrm{bc}$ & $45,1 \mathrm{c}$ & $71,6 \mathrm{a}$ & $10,9 \mathrm{~b}$ & 45,4 & $2507,9 \mathrm{a}$ \\
3 & $10,6 \mathrm{bc}$ & $44,5 \mathrm{c}$ & $68,8 \mathrm{ab}$ & $10,5 \mathrm{~b}$ & 50,1 & $3028,3 \mathrm{a}$ \\
4 & $8,4 \mathrm{c}$ & $51,4 \mathrm{a}$ & $66,5 \mathrm{~b}$ & $10,0 \mathrm{~b}$ & 52,0 & $3134,5 \mathrm{a}$ \\
5 & $12,3 \mathrm{a}$ & $45,5 \mathrm{c}$ & $66,3 \mathrm{~b}$ & $10,9 \mathrm{~b}$ & 49,8 & $2760,4 \mathrm{a}$ \\
8 & $13,4 \mathrm{a}$ & $49,6 \mathrm{ab}$ & $70,9 \mathrm{ab}$ & $11,3 \mathrm{~b}$ & 45,0 & $3149,0 \mathrm{a}$ \\
10 & $13,5 \mathrm{a}$ & $48,4 \mathrm{~b}$ & $66,6 \mathrm{~b}$ & $10,5 \mathrm{~b}$ & 44,3 & $2490,6 \mathrm{a}$ \\
\hline
\end{tabular}

'Médias seguidas pela mesma letra, na coluna, não diferem entre si, pelo teste de Tukey ao nível de $5 \%$.

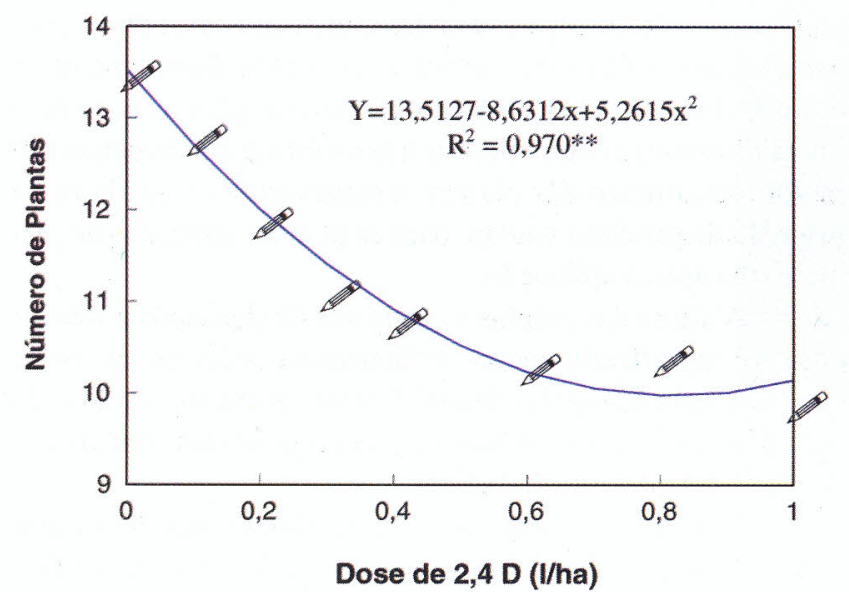

Figura 2. Número de plantas de soja por metro linear em função das doses de 2,4- D nas médias das épocas de semeadura. Rondonópolis-MT, 1999/2000.

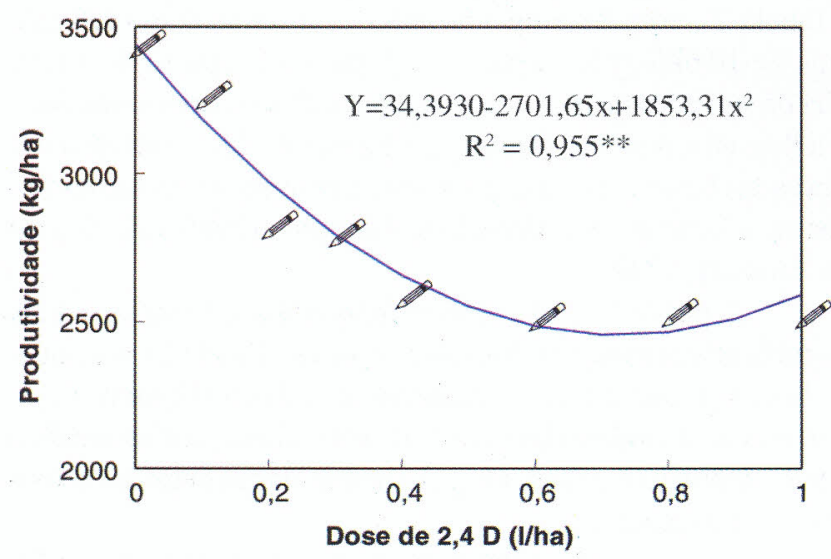

Figura 3. Produtividade da soja em função das doses de 2,4-D, nas médias das épocas de semeadura. Rondonópolis-MT, 1999/2000.

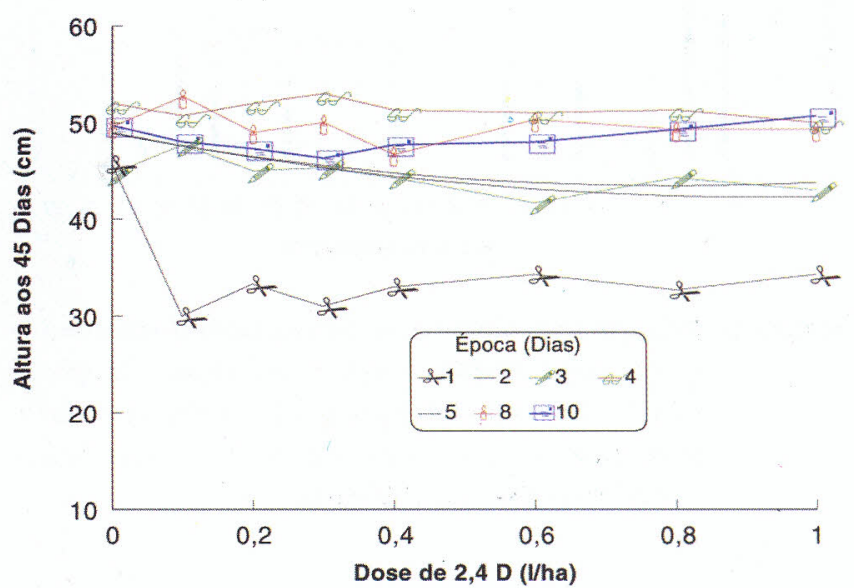

Figura 4. Crescimento das plantas de soja, aos 45 dias após a semeadura, em função do efeito das doses do herbicida 2,4-D. Rondonópolis-MT, 1999/2000.

\section{CONCLUSÕES}

Os resultados indicam que, mesmo em baixa concentração, o 2,4 - D afetou o crescimento da planta de soja, quando semeada até os 6 primeiros dias após a aplicação. A cobertura morta e a precipitação pluviométrica influenciaram o comportamento do herbicida, que interferiu no crescimento e desenvolvimento das plantas. Desse modo, o uso do 2,4-D poderá ser recomendado para solos leves de Cerrados, nas aplicações de dessecação até a dose de $720 \mathrm{~g} / \mathrm{ha}$, desde que aplicado com um intervalo mínimo de 8 dias antes da semeadura direta da soja. 
a)

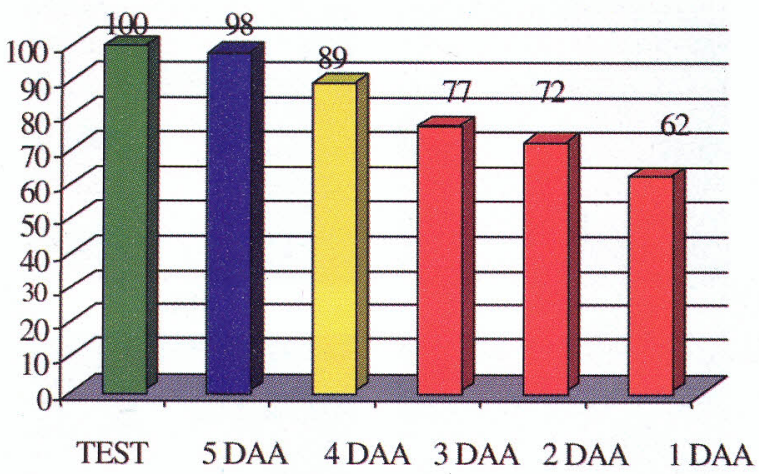

b)

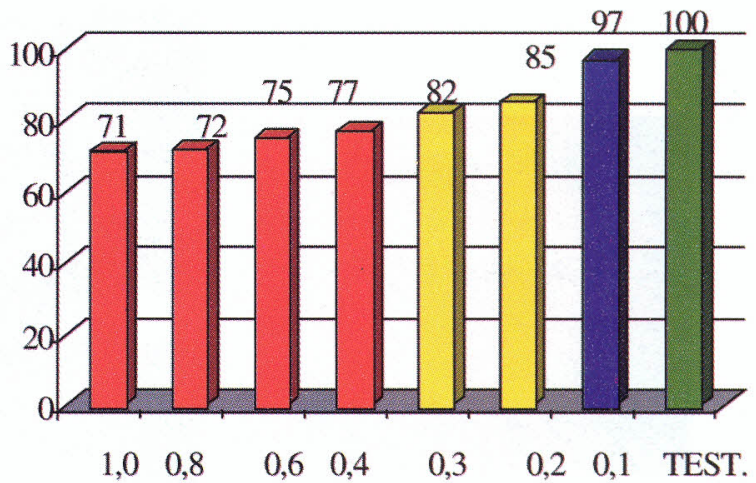

Figura 5. Comportamento da produtividade relativa da soja. a) Na média das doses de 2,4-D em função das diferentes épocas de semeadura. b) Na média das épocas de semeadura em função das diferentes doses de 2,4-D. Rondonópolis-MT, 1999/ 2000.

\section{LITERATURA CITADA}

ALMEIDA, F. S.; RODRIGUES, B. N. Guia de herbicidas: recomendações para uso adequado em plantio direto e convencional. 1 ed. Londrina: IAPAR, 1985.482p.

BLANCO, H. G., OLIVEIRA, D., ARAUJO, J. B. M. Período crítico de competição de uma comunidade natural de mato em soja (Glycine max (L.) Merril.). O Biológico (São Paulo), v. 44, n. 11, p. 299-305, 1978.

EMBRAPA. Centro de Pesquisa Agropecuária do Oeste. Soja: recomendações técnicas para Mato Grosso do Sul e Mato Grosso. Dourados: EMBRAPA-CPAO, 1995. 121p. (EMBRAPA-CPAO. Circular Técnica, 1)

EUCLYDES, R. F. Sistema para análise estatística: SAEG 7.1. Viçosa: Fundação Arthur Bernardes/UFV, 1997.
PITELLI, R.A. Dinâmica de plantas daninhas no sistema plantio direto. In: SIMPÓSIO SOBRE HERBICIDAS EPLANTAS DANINHAS, 1, 1997, Dourados, 1997. Resumos... Dourados: CPAO/EMBRAPA, 1997.

RODRIGUES, B. N.; ALMEIDA, F. S. Guia de herbicidas. 4 ed. Londrina, Edição dos Autores, 1998. 648p.

SATURNINO, H. M. O plantio direto e a integração agropecuária na bovinocultura de leite e de corte nos trópicos. Trabalho apresentado no ciclo de palestras da $35^{a}$ Expoagro, Dourados-MS, 1999. 10 pág. Mimeografado.

VIDAL, R. A . Herbicidas: mecanismos de ação e resistência de plantas. Porto Alegre: Ed. do Autor, 1997. 165p. 
Tarcísio de O. Valente

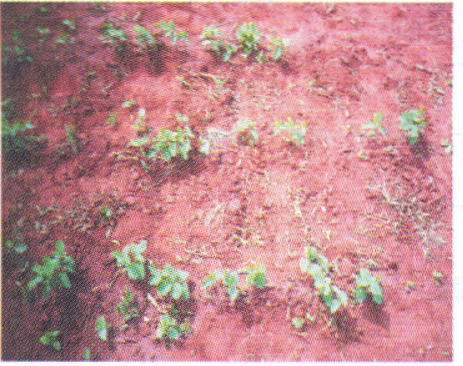

Testemunha 1 DAA

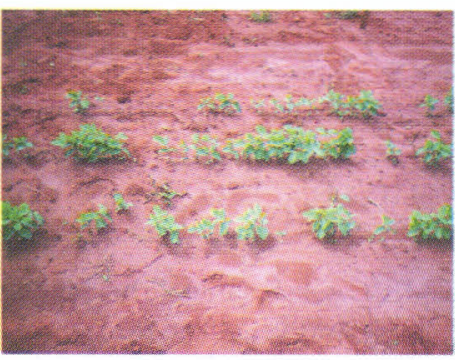

Testemunha 2 DAA

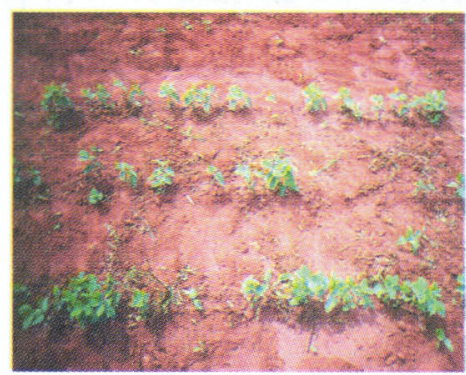

Testemunha 3 DAA

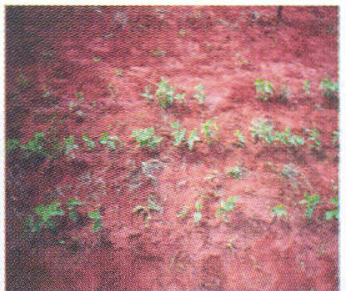

0,2

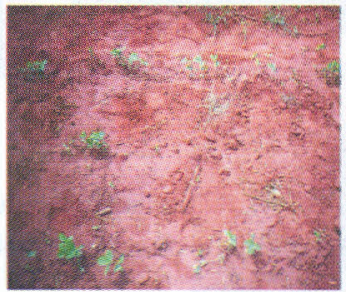

0,6

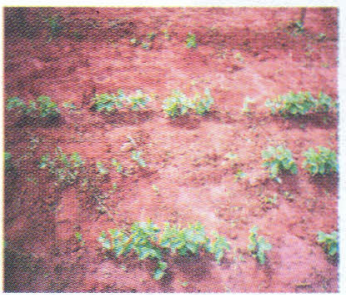

0,2

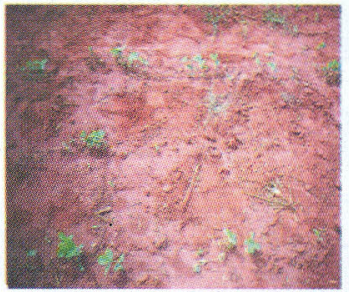

0,6

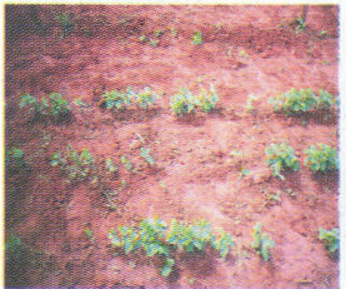

0,2

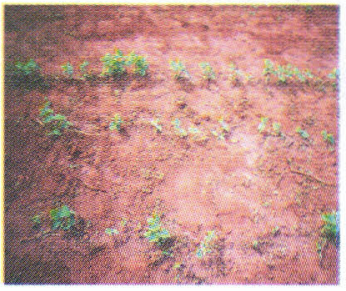

0,6

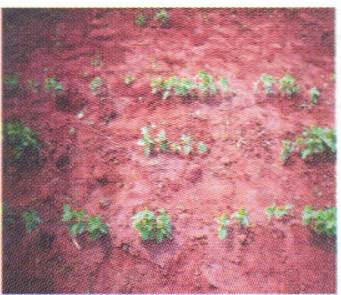

0,3

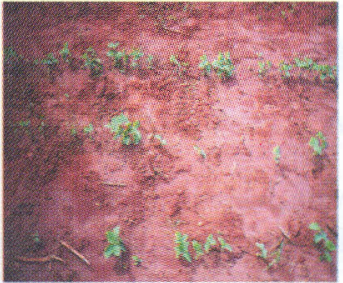

0,8

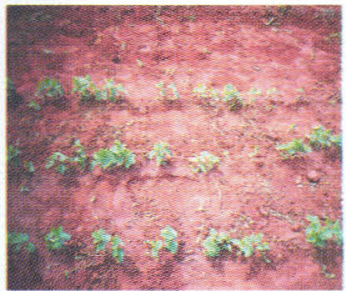

0,3

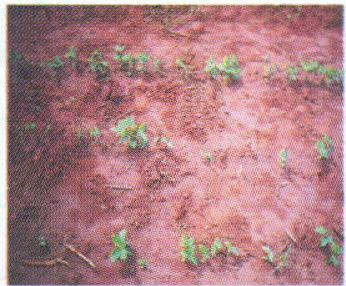

0,8

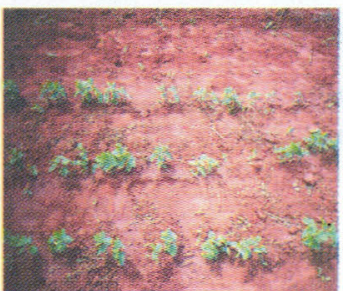

0,3

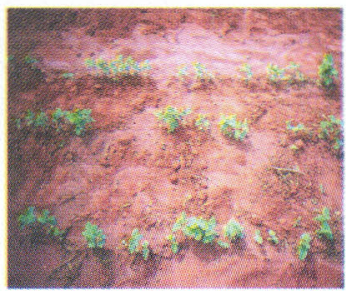

0,8

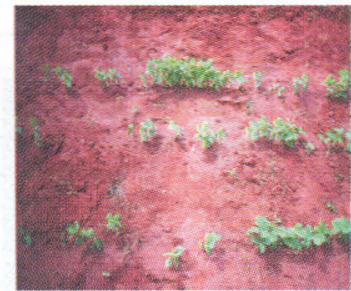

0,4

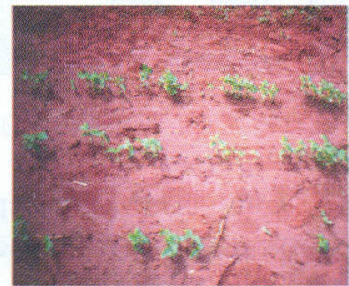

1,0

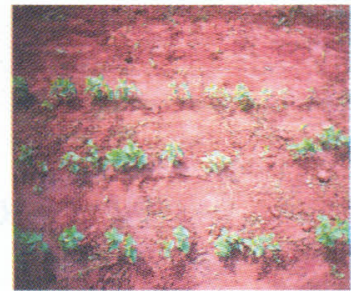

0,4

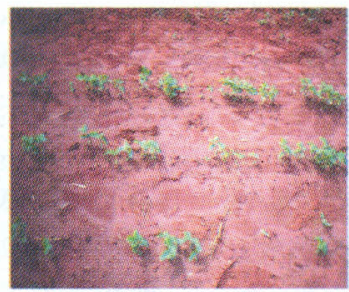

1,0

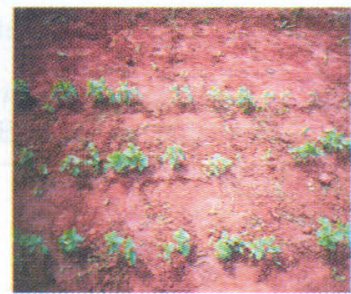

0,4

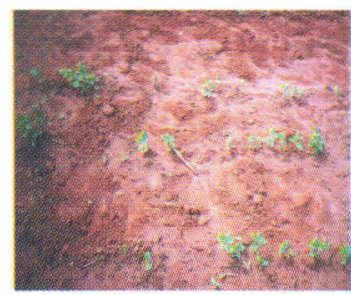

1,0

Figura 6. Sintomas de injúrias provocadas pelo herbicida 2,4-D em plantas de soja, em diferentes doses (em 1/ha), e épocas de semeadura. Rondonópolis-MT, 1999/2000. 